\title{
Interaction of Hindlimb Blood Flow, A-V Shunting and $A-V$ Oxygen Difference ${ }^{1}$
}

\author{
Jack L. Cronenwett, M.D., ${ }^{2}$ John L. Shellito, M.D., Joshua L. LuCE, B.A., \\ James C. Stanley, M.D., AND S. Martin Lindenauer, M.D.
}

Department of Surgery. Division of Peripheral Vascular Surgery. The University of Michigan and The Ann Arbor Veterans Administration Vascular Laboratory, Ann Arbor, Michigan 48105

Presented at the Annual Meeting of the Association for Academic Surgery, San Diego, California, November 7-10, 1982

\begin{abstract}
The interactions of blood flow, $\mathrm{A}-\mathrm{V} \mathrm{O}_{2}$ difference $\left.(\mathrm{AVDO})_{2}\right)$, and $\mathrm{A}-\mathrm{V}$ shunting were measured in normal hindlimbs of nine anesthetized dogs. An aorto-iliac nonpulsatile perfusion pump was used to change femoral artery blood flow from zero (collateral flow only) to twice its baseline level. Femoral $\mathrm{AVDO}_{2}$ was measured by in-line spectrophotometric $\mathrm{O}_{2}$ analysis. A-V shunting was measured with radio-labeled microspheres. Systemic hemodynamic parameters and temperature remained constant during the experiments. Despite changes in femoral mean arterial pressure (160 to $54 \mathrm{~mm} \mathrm{Hg}$ ) and $\mathrm{AVDO}_{2}(1.8$ to $8.2 \mathrm{ml} \mathrm{O} / 2 / \mathrm{dl})$ that occurred with femoral blood flow reduction, peripheral A-V shunting remained constant at 4.1-5.5\%. Alpha-adrenergic ablation (sympathectomy) was used to increase A-V shunting (up to 20\%) during part of this experiment. When hindlimb blood flow was normal or increased, autoregulation of $\mathrm{O}_{2}$ extraction maintained constant hindlimb $\mathrm{O}_{2}$ consumption, despite sympathectomyinduced changes in A-V shunting. Subnormal femoral artery blood flow reduced hindlimb $\mathrm{O}_{2}$ consumption, and in this setting the increased $A-V$ shunting further decreased femoral $A V D O_{2}$ and $\mathrm{O}_{2}$ consumption. Since $\mathrm{AVDO}_{2}$ is dependent upon both blood flow and the variable efficiency of cellular $\mathrm{O}_{2}$ extraction, it cannot be used as an accurate indicator of A-V shunting. Direct microsphere techniques should be applied to A-V shunt measurements in clinical settings where A-V shunting is suspected.
\end{abstract}

\section{INTRODUCTION}

Although peripheral arteriovenous anastomoses (AVAs) have been well documented anatomically, their physiologic function is less well defined [1, 19]. The potential of AVAs to divert large amounts of blood flow away from nutrient capillaries has implicated their involvement in such diverse disease states as septic shock $[4,5,10]$ varicose veins $[3,11]$, arteriosclerosis obliterans $[12,21,24]$ and portal hypertension [20]. Speculation concerning the role of AVAs in these conditions has generally been based upon measurements of peripheral arteriovenous $(\mathrm{A}-\mathrm{V})$ oxygen $\left(\mathrm{O}_{2}\right)$ difference $\left(\mathrm{AVDO}_{2}\right)$, with the assumption that a decreased $\mathrm{AVDO}_{2}$ represented increased an-

\footnotetext{
${ }^{1}$ Supported by the Medical Research Service of the Veterans Administration.

${ }^{2}$ Author to whom requests for reprints should be addressed at University of Michigan Medical Center, 1405 E. Ann Street, Ann Arbor, Mich. 48109.
}

atomic A-V shunting. Since multiple factors influence $\mathrm{AVDO}_{2}$, however, extrapolation from this measurement to conclusions about peripheral A-V shunting is speculative. With radiolabeled microsphere techniques, it is now possible to directly measure A-V shunting and AVA flow [6, 15]. The purpose of this study was to specifically measure the interaction of $\mathrm{AVDO}_{2}, \mathrm{~A}-\mathrm{V}$ shunting, and blood flow in perfused canine hindlimbs.

\section{METHODS}

This experiment was designed to allow local variation in canine hindlimb blood flow while maintaining stable systemic hemodynamic parameters. Mongrel dogs $(22-28 \mathrm{~kg}$ ) were anesthetized with intravenous sodium pentobarbitol $(25 \mathrm{mg} / \mathrm{kg}$ ), with small $(5-\mathrm{mg})$ supplemental doses as necessary to maintain light anesthesia. Pentobarbitol was specifically avoided within $30 \mathrm{~min}$ of $\mathrm{A}-\mathrm{V}$ shunt measurement to avoid changes in A-V shunting associated with acute pentobarbitol admin- 
istration. Animals were intubated and ventilated with room air to maintain normal arterial blood gases. Esophageal temperature was monitored and held constant with a heating mattress and overhead heat lamp. A midline laparotomy was performed, and one external iliac artery was divided, to allow cannulation of the abdominal aorta proximally and the external iliac artery distally. Silastic tubing (3.2 $\mathrm{mm}$ i.d.) was then routed from the aorta through a variable-speed roller pump to the external iliac artery. All arterial branches between the aortic bifurcation and the superficial femoral artery were ligated to decrease available hindlimb collateral circulation. An appropriate-size electromagnetic flow probe (previously calibrated in vivo) was placed on the superficial femoral artery. Baseline femoral artery blood flow was recorded prior to division and cannulation of the external iliac artery. Animals were systemically heparinized (200 units $/ \mathrm{kg}$ ) prior to establishing aorto-iliac pump flow.

A small muscular branch of the superficial femoral artery was cannulated to record femoral mean arterial pressure (MAP) and to administer microspheres for A-V shunt measurement (see below). Systemic MAP and heart rate (HR) were recorded via the carotid artery. Cardiac output and pulmonary artery (PA) temperature were recorded using a transjugular Swan-Ganz catheter and a thermodilution cardiac output computer. Cardiac index (CI), total peripheral resistance (TPR), and hindlimb resistance were calculated as previously described [9].

The femoral vein was cannulated via a small muscular branch for continuous, in-line measurement of hindlimb $\mathrm{AVDO}_{2}$. Venous blood from this catheter and arterial blood from a brachial artery catheter were pumped with a constant-speed tandem roller pump through an in-line spectrophotometric $\mathrm{O}_{2}$ analyzer (AVox Systems), which was calibrated in vivo with a Lex- $\mathrm{O}_{2}$-Con oxygen analyzer (Lexington Instruments). Since total hindlimb flood flow was not measured, femoral artery flow was used to estimate hindlimb $\mathrm{O}_{2}$ consumption as:

$$
\begin{aligned}
& \mathrm{O}_{2} \text { consumption }=\text { femoral } \mathrm{AVDO}_{2} \\
& \left(\mathrm{ml} / \mathrm{O}_{2} \mathrm{~min}\right) \quad(\mathrm{ml} \mathrm{O} / \mathrm{dl}) \\
& \times \text { femoral artery flow } \times 0.01 \text {. } \\
& (\mathrm{ml} / \mathrm{min}) \quad(\mathrm{dl} / \mathrm{ml})
\end{aligned}
$$

To calculate hindlimb $\mathrm{O}_{2}$ consumption at zero femoral artery flow, it was necessary to estimate hindlimb collateral blood flow. Based upon previous studies of femoral artery ligation, hindlimb collateral flow was estimated to represent $20 \%$ of normal femoral artery flow during the 15-min period analyzed after femoral flow cessation [14]. Collateral flow was considered insignificant at femoral flow rates $0.5-2.0 \times$ baseline and was not included in $\mathrm{O}_{2}$ consumption calculations for these flow rates. This estimate did not affect $\mathrm{AVDO}_{2}$, which was directly measured at zero femoral artery flow.

Hindlimb A-V shunting was measured using a previously described radiolabeled $\mathrm{mi}$ crosphere technique [6-8]. Radiolabeled microspheres $(25 \pm 10 \mu \mathrm{m}$ diam) that pass through hindlimb AVAs after femoral artery injection become trapped in pulmonary capillaries and are measured by external thoracic scintillation detection. Comparison of this value to that obtained after a femoral venous injection (representing 100\% shunting) allows multiple sequential measurements of peripheral A-V shunting.

In Part I of this experiment, the effect of changes in femoral blood flow upon hindlimb A-V shunting and $\mathrm{AVDO}_{2}$ was determined in seven dogs using the above-described preparation. By adjusting the aorto-iliac pump, femoral artery blood flow was subsequently varied from zero to twice baseline flow in increments of $0.5 \times$ baseline flow. The above parameters were measured after they had stabilized at each flow rate, allowing $15 \mathrm{~min}$ for stabilization between measurements.

In Part II of this study, the effect of artificially increased A-V shunting was determined on the above variables. To increase A-V shunting from baseline levels, a lumbar sympathectomy (L2-L4) was performed through a midline incision in nine dogs. Lumbar sympathectomy has previously been demonstrated 
in our laboratory to significantly increase A-V shunting by alpha-adrenergic ablation $[6,8]$. Simultaneous measurements of $\mathrm{AVDO}_{2}$ and $\mathrm{A}-\mathrm{V}$ shunting were then made at femoral artery flow rates ranging from zero to twice baseline at increments of $0.5 \times$ baseline. Since sympathectomy produces initially maximal A-V shunting, which then decreases over 1$2 \mathrm{hr}$, it was possible to examine the effect of several different $\mathrm{A}-\mathrm{V}$ shunt values in each animal by obtaining data points at different times during $2 \mathrm{hr}$ post sympathectomy. Since the magnitude of the effect of sympathectomy on A-V shunting varies in each animal, not all dogs could be studied at each flow rate and equivalent $\mathrm{A}-\mathrm{V}$ shunt value. For data analysis, shunt rates were grouped as: $0-5,5-10$, and $10-20 \%$ A-V shunting and were analyzed by nonpaired statistical techniques to reflect the independence of these observations.

In Part I, each variable measured at the five different femoral artery flow rates was initially tested for statistical significance by analysis of variance. Where significant $(P<0.05)$ variance existed, the paired Student $t$ test was applied to define significant differences of these variables at successive femoral artery flow rates. In Part II, analysis of variance was used to assess the effect of both femoral artery flow rate (five categories) and $\mathrm{A}-\mathrm{V}$ shunting (three categories) upon $\mathrm{AVDO}_{2}$ and $\mathrm{O}_{2}$ consump- tion. When significant variance $(P<0.05)$ was obtained, nonpaired Student's $t$ test (assuming unequal variance) was used to compare these variables at successive flow rates or between different $\mathrm{A}-\mathrm{V}$ shunt categories.

\section{RESULTS}

\section{Part I}

Mean baseline femoral artery blood flow prior to aorto-iliac pump insertion was 110 $\mathrm{ml} / \mathrm{min}$. After pump insertion, alteration of femoral artery flow rate from 0 to $2.0 \times$ baseline produced no significant change in MAP, CI, TPR, HR, or PA temperature (Table 1). Femoral artery MAP (measured distal to the aorto-iliac pump) increased from 53 to 160 $\mathrm{mm} \mathrm{Hg}$ as femoral artery flow was increased from zero to twice baseline. This increase in MAP was significant at each increment of femoral blood flow ( $P<0.01$, Table 2 ). Correspondingly, hindlimb vascular resistance decreased significantly with each incremental increase of femoral artery blood flow (Table 2). Changes in femoral artery flow resulted in considerable change in hindlimb $\mathrm{AVDO}_{2}$ (Table 2). When femoral blood flow increased above baseline $(1.5 \times, 2.0 \times), \mathrm{AVDO}_{2}$ decreased from 3.2 to $1.8 \mathrm{ml} \mathrm{O} / \mathrm{dl}$, to yield no net change in calculated $\mathrm{O}_{2}$ consumption (3.4$3.7 \mathrm{ml} \mathrm{O}_{2} / \mathrm{min}$ ) (Figs. 1 and 2). When femoral

TABLE 1

EFfect of Hindlimb Blood Flow upon Systemic Hemodynamic PaRameters

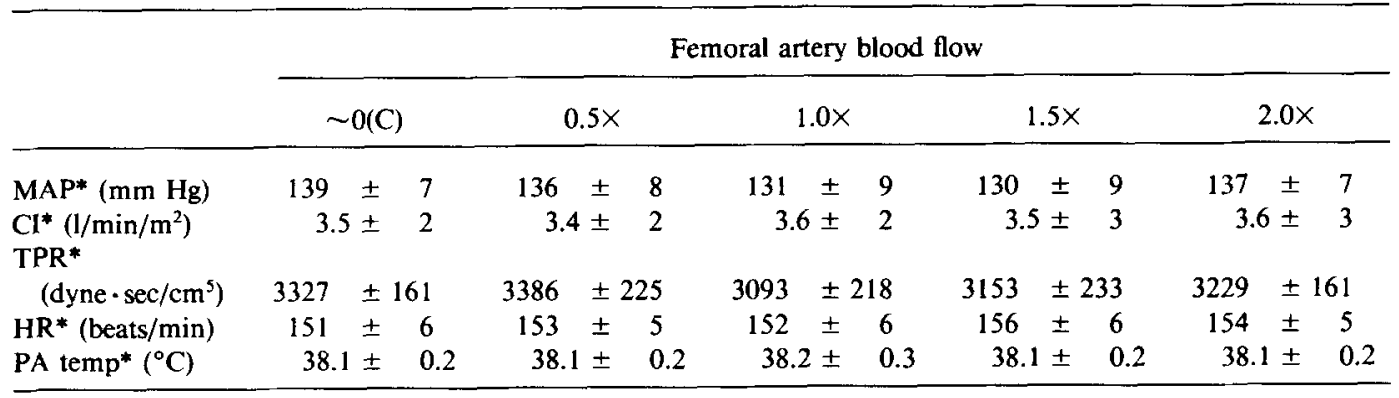

Notes. $n=$ seven dogs, $\bar{x} \pm$ SEM.

Abbreviations: $\times$, baseline femoral artery flow before perfusion pump (110 $\mathrm{ml} / \mathrm{min}) ; \mathrm{C}$, collateral flow in hindlimb with perfusion pump off; MAP, mean arterial pressure; CI, cardiac index; TPR, total peripheral resistance; HR, heart rate; PA temp, pulmonary artery temperature.

* No significant change at indicated flow rates. 
TABLE 2

EFFeCt of Femoral Blood Flow Rate upon Hindlimb A-V Shunting and A-V Oxygen Difference

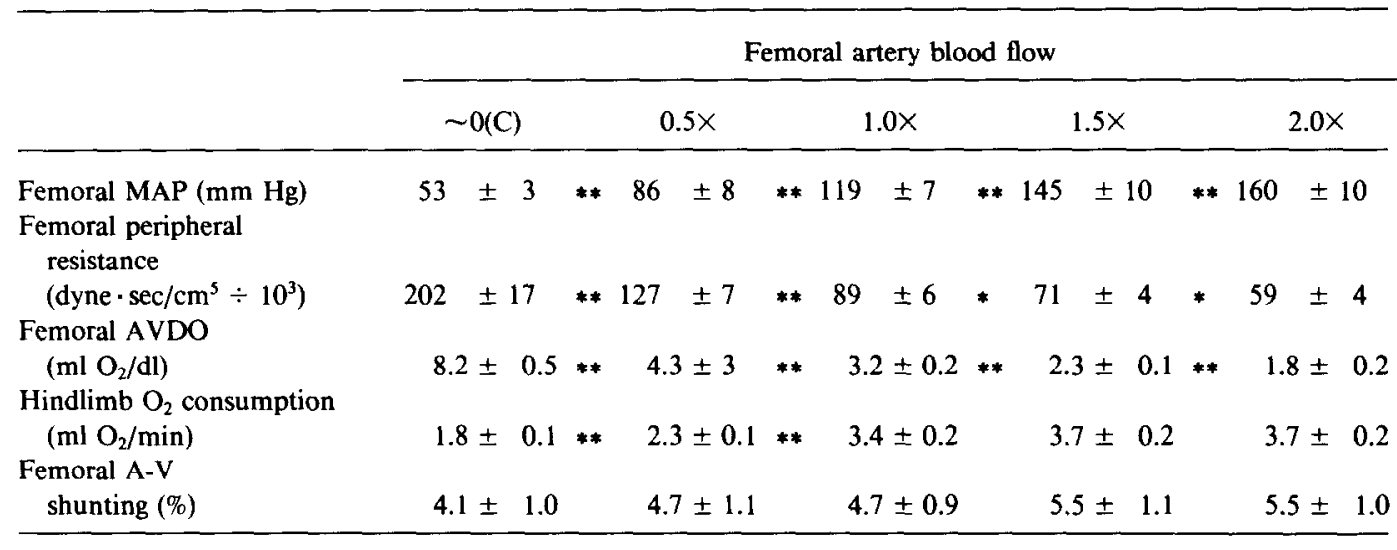

Notes. $n=7, \bar{x} \pm$ SEM. Abbreviations: $\times$, baseline femoral artery flow prior to perfusion pump $(110 \mathrm{ml} / \mathrm{min})$; C, collateral flow in hindlimb with perfusion pump off; MAP, mean arterial pressure; $\mathrm{AVDO}_{2}$, arteriovenous oxygen difference.

* $P<0.05$, difference between successive flow rates, paired Student's $t$ test.

** $P<0.01$, difference between successive flow rates, paired Student's $t$ test.

artery blood flow decreased $(0.5$ and $0 \times$ baseline), femoral $\mathrm{AVDO}_{2}$ increased significantly (from 3.2 to 4.3 and $8.2 \mathrm{ml} \mathrm{O}_{2} / \mathrm{dl}$, respectively). At these low flow rates, calculated hindlimb $\mathrm{O}_{2}$ consumption also decreased, from 3.4 to 2.3 and $1.8 \mathrm{ml} \mathrm{O}_{2} / \mathrm{min}$, respectively (Table 2, Fig. 2). The calculated $\mathrm{AVDO}_{2}$ that would have been required to maintain constant $\mathrm{O}_{2}$ consumption despite changes in blood flow is shown by the broken line in Fig. 1. At flow rates higher than baseline, $\mathrm{AVDO}_{2}$ decreased as predicted, to maintain constant $\mathrm{O}_{2}$ consumption. At lower than baseline flow rates, however, actual increases in $\mathrm{AVDO}_{2}$ were insufficient to maintain stable $\mathrm{O}_{2}$ consumption.

Despite the above changes in femoral artery flow, femoral MAP, and hindlimb $\mathrm{AVDO}_{2}$, hindlimb A-V shunting remained constant during this study, varying insignificantly between 4.1 and $5.5 \%$ (Table 2).

\section{Part II}

Mean baseline femoral artery flow was 118 $\mathrm{ml} / \mathrm{min}$ prior to aorto-iliac pump placement. As shown in Table 3, both femoral $\mathrm{AVDO}_{2}$ and hindlimb $\mathrm{O}_{2}$ consumption varied considerably with changes in femoral artery blood flow, analogous to the observation in Part I. At baseline or higher than baseline flow rates $(X, 1.5 \times, 2.0 \times)$ increased A-V shunting had no significant effect on either $\mathrm{AVDO}_{2}$ or $\mathrm{O}_{2}$ consumption (Table 3, Fig. 3). At lower than baseline flow rates $(0.5 \times, 0 \times)$, however, 10 -

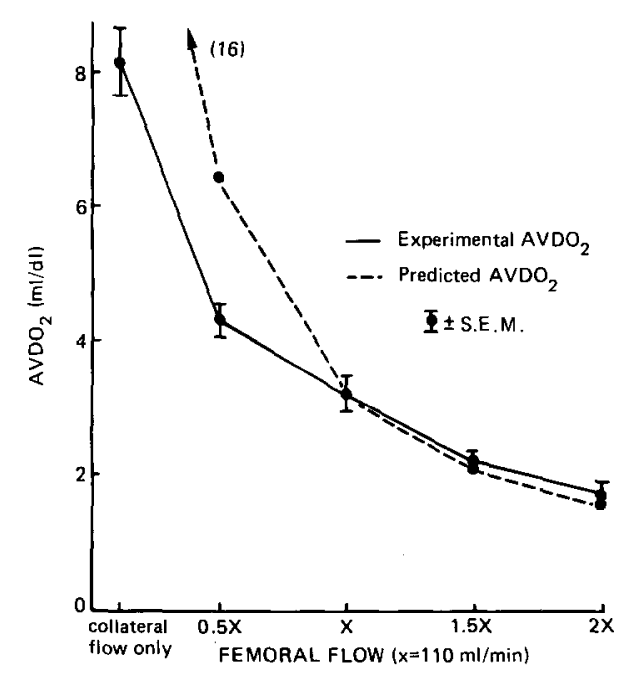

FIG. 1. Femoral $\mathrm{AVDO}_{2}$ at femoral artery blood flow varying from zero (collateral flow only) to twice $(2 \times)$ baseline flow. Predicted $\mathrm{AVDO}_{2}$ is that which would have been required to maintain $\mathrm{O}_{2}$ consumption equivalent to that measured at baseline $(X)$ flow. Note significant deviation from predicted $\mathrm{AVDO}_{2}$ at low flow. 


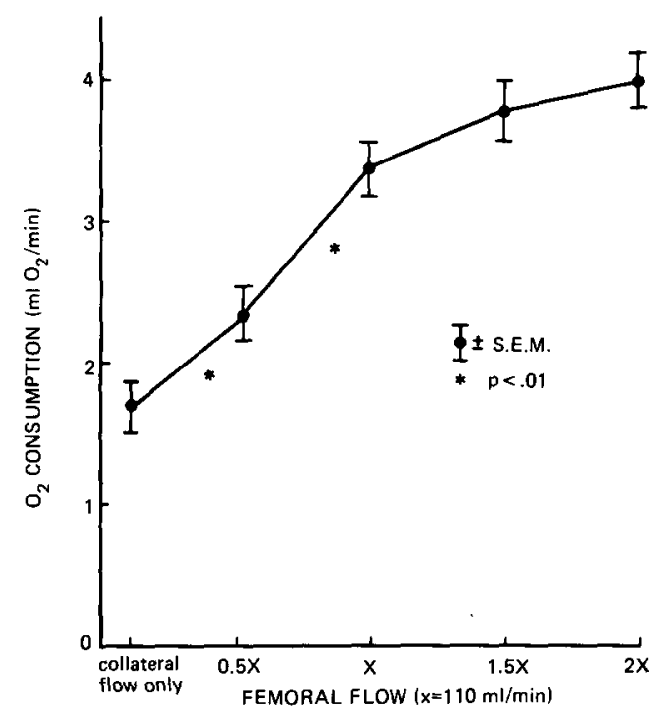

FIG. 2. Hindlimb $\mathrm{O}_{2}$ consumption at femoral artery flow rates varying from zero (collatcral flow only) to twice (2x) baseline flow. Note significant decreases in $\mathrm{O}_{2}$ consumption at less than normal baseline flow rates.

$20 \%$ A-V shunting caused a significant reduction in $\mathrm{AVDO}_{2}$ and $\mathrm{O}_{2}$ consumption, compared to that seen at less than $5 \%$ shunting $(P<0.03$, Fig. 3, Table 3). Intermediate A$\mathrm{V}$ shunting $(5-10 \%)$ resulted in hindlimb $\mathrm{AVDO}_{2}$ and $\mathrm{O}_{2}$ consumption that were intermediate to that seen at low (0-5\%) and high (10-20\%) A-V shunting (Table 3, Fig. 3).

\section{DISCUSSION}

In this experiment, hindlimb A-V shunting was varied by lumbar sympathectomy over a range that we have previously demonstrated to occur in dogs following pharmacologic alpha-adrenergic blockade [6], after sympathectomy [8], or during local hindlimb infection [7]. Preliminary studies by ourselves (unpublished data) and others using the same microsphere techniques in humans suggest. that a $0-20 \%$ range of peripheral A-V shunting is also observed clinically $[15,21]$. Despite these moderately large diversions of hindlimb blood flow away from nutrient capillaries, minimal and statistically insignificant changes in $\mathrm{O}_{2}$ consumption were observed in this study, at normal or increased blood flow rates, presumably due to the ability of the animals to regulate (increase) $\mathrm{O}_{2}$ extraction. Only at low flow rates where significantly reduced $\mathrm{O}_{2}$ consumption was noted did incrcased A-V shunting further reduce peripheral $\mathrm{O}_{2}$ consumption. At such low flow rates, however, $\mathrm{AVDO}_{2}$ was much more dependent upon changes in total blood flow than upon changes in anatomic A-V shunting. Thus, the ability to infer even qualitative variations in peripheral $\mathrm{A}-\mathrm{V}$ shunting based upon changes in hindlimb $\mathrm{AVDO}_{2}$ is poor at the shunt ranges studied in the experiment. Furthermore, any

TABLE 3

EFfect of ARteriovenous Shunting and Femoral Artery Blood Flow upon HINDLIMB ARTERIOVENOUS OXYGEN DIFFERENCE

\begin{tabular}{|c|c|c|c|c|c|c|c|c|}
\hline & \multirow{2}{*}{$\begin{array}{c}\text { A-V shunt } \\
(\%)\end{array}$} & \multicolumn{7}{|c|}{ Femoral artery blood flow } \\
\hline & & & $\sim 0(\mathrm{C})$ & & $0.5 \times$ & $1.0 \times$ & $1.5 \times$ & $2.0 \times$ \\
\hline $\begin{array}{l}\text { Femoral AVDO } \\
\qquad\left(\mathrm{ml} \mathrm{O} \mathrm{O}_{2} / \mathrm{dI}\right)\end{array}$ & $\begin{array}{c}0-5 \\
5-10 \\
10-20\end{array}$ & $\#$ & {$\left[\begin{array}{l}7.9 \pm 0.6 \\
7.3 \pm 0.4 \\
5.7 \pm 0.4\end{array}\right.$} & $\begin{array}{l}* \\
*\end{array}$ & {$\left[\begin{array}{l}4.4 \pm 0.2 \\
3.8 \pm 0.4 \\
3.1 \pm 0.4\end{array}\right.$} & $\begin{array}{l}* 3.3 \pm 0.2 \\
2.8 \pm 0.2 \\
2.7 \pm 0.3\end{array}$ & $\begin{array}{l}* 2.3 \pm 0.1 \\
* \quad 2.1 \pm 0.1 \\
2.1 \pm 0.4\end{array}$ & $\begin{array}{l}1.8 \pm 0.2 \\
1.7 \pm 0.2 \\
1.8 \pm 0.2\end{array}$ \\
\hline $\begin{array}{c}\text { Hindlimb oxygen } \\
\text { consumption } \\
\text { ( } \mathrm{ml} \mathrm{O}_{2} / \mathrm{min} \text { ) }\end{array}$ & $\begin{array}{c}0-5 \\
5-10 \\
10-20\end{array}$ & $\#$ & {$\left[\begin{array}{l}1.9 \pm 0.1 \\
1.8 \pm 0.1 \\
1.3 \pm 0.1\end{array}\right.$} & $\begin{array}{l}* \\
*\end{array}$ & {$\left[\begin{array}{l}2.6 \pm 0.1 \\
2.2 \pm 0.2 \\
1.9 \pm 0.2\end{array}\right.$} & $\begin{array}{l}3.9 \pm 0.2 \\
3.3 \pm 0.2 \\
3.2 \pm 0.4\end{array}$ & $\begin{array}{l}* \quad 4.1 \pm 0.2 \\
* \quad 3.8 \pm 0.2 \\
\\
3.8 \pm 0.2\end{array}$ & $\begin{array}{l}4.2 \pm 0.5 \\
4.0 \pm 0.5 \\
4.2 \pm 0.5\end{array}$ \\
\hline
\end{tabular}

Notes. $n=9, \bar{x} \pm$ SEM. Abbreviations: $C$, collateral flow in hindlimb with perfusion pump off; $\times$, basline femoral artery flow before perfusion pump (118 ml/min); $\mathrm{AVDO}_{2}$, arteriovenous oxygen difference.

Comparison by nonpaired Student's $t$ test:

* $P<0.03$, difference between successive flow rates.

$* P<0.03$, difference between $A-V$ shunt ranges at same flow rate. 


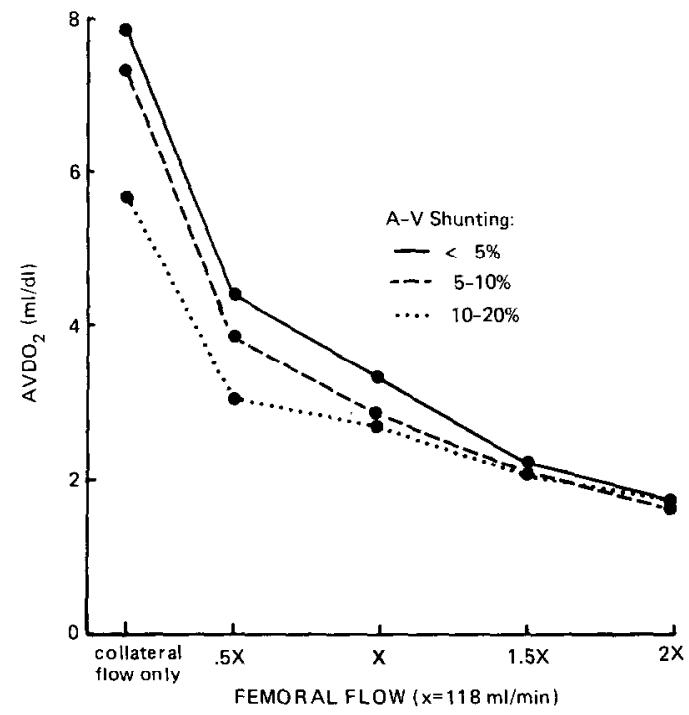

FIG. 3. Effect of different amounts of A-V shunting on femoral $\mathrm{AVDO}_{2}$ at different femoral artery blood flow rates. Note the lack of effect of A-V shunting at normal or increased flow, but the significant reduction of $\mathrm{AVDO}_{2}$ in the presence of $10-20 \%$ A-V shunting at decreased flow rates $(P<0.03)$.

relationship between $\mathrm{A}-\mathrm{V}$ shunting and $\mathrm{AVDO}_{2}$ is dependent upon assumptions of constant blood flow and metabolic rate that are often absent in clinical situations where these variables are of interest.

The hindlimb perfusion system used in this experiment, combined with in-line $\mathrm{AVDO}_{2}$ analysis [18], afforded reproducible data, with measured $\mathrm{AVDO}_{2}$ being nearly identical to the $\mathrm{AVDO}_{2}$ predicted to maintain constant $\mathrm{O}_{2}$ consumption at different flow rates (Fig. 1). The effect of nonpulsatile, roller-pump perfusion upon peripheral $\mathrm{O}_{2}$ consumption, compared to pulsatile perfusion, has previously been shown to be negligible [13]. Previous studies from our laboratory have shown that hindlimb perfusion per se has no significant effect on A-V shunting, including the potential influence of periarterial sympathetic nerve dissection [17]. Baseline A-V shunt values in this study (4-6\%) agree with previous studies not employing such perfusion pumps and confirm the lack of influence of this preparation upon measured A-V shunting [6-9, $15,21]$. Peripheral A-V shunting in normothermic dogs was quite uniform in this ex- periment. This coincides with previous data from our laboratory using similar techniques [6-9]. Core temperature, as important influence upon A-V shunting, was carefully controlled in this study. While hindlimb temperature was not measured in this experiment, previous data from our laboratory using a comparable animal preparation demonstrated insignificant changes in paw temperature, even when large increases in A-V shunting occurred $[6,7]$. Predicted peripheral temperature changes of $<1^{\circ} \mathrm{C}$ would not have been sufficient to alter hindlimb metabolism enough to cause the large changes in $\mathrm{AVDO}_{2}$ observed in the current study. The observation that AVAs were not affected by large changes in flow and pressure but were affected considerably by sympathetic ablation emphasizes the role of the autonomic nervous system in the regulation of AVAs, as we have previously shown $[6,8]$.

Results of this study concerning the differential effect of A-V shunting upon oxygen consumption at different flow rates may help explain different clinical results following lumbar sympathectomy [2], a procedure known to increase AVA flow rather than nutrient capillary flow [8, 21]. Several investigators have suggested that only patients with moderately good peripheral blood flow respond favorably to lumbar sympathectomy. In this regard, a positive clinical response has been predicted by an ankle-brachial index greater than 0.35 [23], a distal-thigh index greater than 0.7 [16], or an absolute ankle pressure greater than $30 \mathrm{~mm} \mathrm{Hg}$ [22]. Despite the effect of sympathectomy to increase nonnutritive AVA flow, a potential benefit of this procedure may be the stimulation of increased collateral blood flow due to the pressure gradicnt created by distal vasodilatation. Although such improved collateral blood flow may not persist beyond the 6-8 week hyperemic period following sympathectomy, this is a common explanation for beneficial effects of this procedure. Results of the current study would support the concept that patients with only moderately reduced peripheral blood flow could respond favorably to sympathectomy. This would be due to their ability to increase 
cellular oxygen extraction sufficiently to overcome increased AVA flow seen during the acute hyperemic period, perhaps resulting in a net gain in oxygen delivery. Patients with very low blood flow, however, probably have cellular oxygen extraction that is already maximal and is unable to compensate for increased AVA flow associated with sympathectomy. This would result in a nel decrease in total $\mathrm{O}_{2}$ consumption, despite increased collateral blood flow, analogous to the results noted during low femoral blood flow and high $\mathrm{A}-\mathrm{V}$ shunting in our current animal experiment. Although this hypothesis requires direct clinical testing, it may help explain the variable response of patients to sympathectomy, as related to the level of preexisting extremity blood flow, defined by the noninvasive laboratory studies referred to above.

Results of this study strongly suggest that previous investigations using indirect $\mathrm{AVDO}_{2}$ measurement to assess the role of peripheral A-V shunting should be reexamined. The microsphere technique for A-V shunt measurement described in this report is applicable to human use. Direct shunt measurement in clinical disorders where A-V shunting has been implicated is required to accurately quantitate the patho-physiologic role of AVAs in human disease.

\section{REFERENCES}

1. Abramson, D. I. Pathophysiology of arteriovenous shunts in the extremities. J. Cardinvasc. Surg. 6(Suppl.): 217, 1965.

2. Bergan, J. J., and Trippel, O. H. Arteriograms in ischemic limbs worsened after lumbar sympathectomy. Arch. Surg. 85: 643, 1962.

3. Blumoff, R. L., and Johnson, G. Saphenous vein $\mathrm{pO}_{2}$ in paticnts with varicose vcins. J. Surg. Res. 23: 35, 1977.

4. Borderg, J. R., Gallo, E., and Schenk, W. G., Jr. Systemic arteriovenous shunts in patients under severe stress: A common cause of high output cardiac failure. Surgery 60: 225, 1966.

5. Cohn, J. D., Greenspan, M., Goldstein, C. R., Gudwin, A. L., Siegel, J. H., and Del Guercio, L. R. M. Arteriovenous shunting in high cardiac output shock syndromes. Surg. Gynecol. Obstet. $127: 282,1968$.

6. Cronenwett, J. L., and Lindenauer, S. M. Direct measurement of arteriovenous anastomotic blood flow after lumbar sympathectomy. Surgery 82: 82, 1977.

7. Cronenwett, J. L., and Lindenauer, S. M. Direct mea- surement of arteriovenous anastomotic blood flow in the septic canine hindlimb. Surgery 85: 275, 1979.

8. Cronenwett, J. L., and Lindenauer, S. M. Hemnodynamic effects of sympathectomy in ischemic canine hindlimbs. Surgery 87: 417, 1980.

9. Cronenwett, J. L., and Lindenauer, S. M. Hemodynamic effects of cecal ligation sepsis in dogs. J. Surg. Res. 33: 324, 1982.

10. Duff, J. H., Groves, A. C., McLean, A. P. H., LaPointe, R., and MacLean, L. D. Defective oxygen consumption in septic shock. Surg. Gynecol. Obstet. 128: 1051, 1969.

11. Haimovici, H. Abnormal arteriovenous shunts associated with chronic venous insufficiency. J. Cardiovasc. Surg. 16: 476, 1976.

12. Haimovici, H., Steinman, C., and Caplan, H. L. Role of arteriovenous anastomoses in vascular disease of the lower extremity. Ann. Surg. 164: 990, 1966.

13. Harken, A. H. The influence of pulsatile perfusion on oxygen uptake by the isolated canine hindlimb. J. Thor. Cardiovasc. Surg. 70, 237, 1975.

14. John, H. T., and Warren, R. The stimulus to collateral circulation. Surgery 49: 14, 1961.

15. Plecha, F. R., Bomberger, R. A., Hoffman, M., and MacPherson, K. M. A new criterion for predicting response to lumbar sympathectomy in patients with severe arteriosclerotic occlusive disease. Surgery 88: $375,1980$.

16. Rhodes, B. A., Rutherford, R. B., Lopez-Majano, V., Greyson, N. D., and Wagner, H. N. Arteriovenous shunt measurements in extremities. J. Nucl. Med. 13: $237,1972$.

17. Shellito, J. L., Cronenwett, J. L., Osment, M. L., I uce, J. L., Sheagren, J. N., and I indenauer, S. M. Effect of Staphylococcus aureus on canine peripheral oxygen consumption and arteriovenous shunting. Surg. Forum 33: 35, 1982.

18. Shepherd, A. P., Burgar, C. G. A solid-state arteriovenous oxygen difference analyzer for flowing whole blood. Amer. J. Physiol. 232: H437, 1977.

19. Sherman, J. L., Jr. Normal arteriovenous anastomoses. Medicine 42: 247, 1963.

20. Turcotte, J. G. Portal hypertension as I see it. In C. G. Child (Ed.) Portal Hypertension, Saunders: Philadelphia, 1974. Pp. 78-111.

21. Waibel, P. P., Locher, J. T., Dunant, J. H., and Fridrich, $R$. Increase of arteriovenous shunts after lumbar sympathectomy. J. Cardiovasc. Surg. 14(Suppl): 638, 1973.

22. Walker, P. M., and Johnston, K. W. Predicting the success of a sytmpathectomy: A prospective study using discriminant analysis function and multiple regression analysis. Surgery 87: 216, 1980.

23. Yao, J.S. T., and Bergan, J. J. Predictability of vascular reactivity relative to sympathetic ablation. Arch. Surg. 107: 676, 1973.

24. Young, R. S., Pochazevsky, R., and Bryk, D. Occlusive peripheral arterial disease. Spontaneous arteriovenous shunting. N. Y. State J. Med. 76: 408, 1976. 